\title{
Certificação LEED: A reforma sustentável do estádio Mineirão e suas vantagens
}

\author{
LEED Certification: The sustainablereformofthe Mineirão stadiumand itsadvantages \\ Matheus Silva Rodrigues*, Monique Brum Pereira, Renata Lemos da Cunha Gomes, Bárbara Braga \\ Barbosa
}

Como citar esse artigo. Rodrigues, MS; Pereira, MB; Gomes, RLC; Barbosa, BB. Certificação LEED: A reforma sustentável do estádio Mineirão e suas vantagens. Revista Teccen. 2019 Jul/Dez; 12 (2): 30-38.

\begin{abstract}
Resumo
A preservação ambiental é um tema cada vez mais discutido no mundo, atualmente já existem leis para regularizar ações que antigamente eram consideradas rotineiras. Como na construção civil, que é considerada uma dos maiores vilãs em uso de recursos naturais e poluição, assim como no cenário mundial o setor da construção civil também teve que se adequar, com isso surgiu a implementação de novos métodos e novas tecnologias construtivas para aperfeiçoar as construções tornando-as economicamente e ambientalmente viáveis. Um exemplo disso são certificações ambientais que têm como objetivo a criação de edifícios sustentáveis, que permitem a economia de materiais e recursos e também dá autonomia a edificação. Por meio de revisão bibliográfica esse trabalho tem como objetivo levantar dados sobre a reforma do estádio Governador Magalhães Pinto, conhecido como Mineirão, que foi reformado ao molde dos requisitos da Certificação LEED, conquistando o nível mais elevado da certificação, gerando economia no uso de água potável, energia elétrica, de insumos para obra, entre outros benefícios ambientais, financeiros e sociais, analisando os prós e contras que a sociedade encontra na busca pela certificação. Com esse estudo é possível afirmar que os edifícios sustentáveis geram excelentes economias em longo prazo, pois são autossuficientes, porém requerem um investimento financeiro inicial mais elevado do que uma construção convencional.
\end{abstract}

Palavras-Chave: Sustentabilidade; Construção Civil; Economia; Recursos Naturais.

\begin{abstract}
Environmental preservation is a topic that is increasingly discussed in the world, currently there are laws to regulate actions that were once considered routine. As in construction, which is considered one of the greatest villains in the use of natural resources and pollution, just as in the world scenario the civil construction sector also had to adapt, with this came the implementation of new methods and new constructive technologies to perfect making them economically and environmentally viable. An example of this are environmental certifications that have as objective the creation of sustainable buildings, that allow the saving of materials and resources and also gives autonomy the edification. Through a bibliographic review, this work aims to collect data on the reform of the Governador Magalhães Pinto Stadium, known as Mineirão, which was reformed to the mold of LEED Certification requirements, achieving the highest level of certification, generating savings in water use potable water, electricity, raw materials, among other environmental, financial and social benefits, analyzing the pros and cons that society finds in the search for certification. With this study it is possible to affirm that sustainable buildings generate excellent long-term savings because they are self sufficient, but require an initial financial investment higher than a conventional construction.
\end{abstract}

Keywords: Sustainability; Construction; Economy; Natural Resources.

\section{Introdução}

Nas últimas duas décadas o termo sustentabilidade vem sendo cada vez mais discutido, porém já é um assunto pautado há mais de quatro décadas. Em Estocolmo, Suécia, em junho de 1972 aconteceu a primeira grande conferência voltada para a discussão da degradação do meio ambiente, a Declaração de Estocolmo tinha como objetivo pautar medidas a serem tomadas para desacelerar os impactos ambientais causados pelas atividades humanas. No entanto, os objetivos almejadospelo evento não foram atingidos quando observado o desequilíbrio entre a preservação do meio ambiente e o desenvolvimento da sociedade anos depois.(Senado Federal, 2012)

Em 1992 houve uma nova conferência mundial. A ECO-92, realizada no Rio de Janeiro, Brasil, foi criada com o intuito de discutir os danos causados ao meio ambiente comparando com os progressos atingidos até então. Esta conferência foi de extrema importância, pois teve a participação de grandes

Afiliação dos autores: Universidade de Vassouras - UV, Vassouras - RJ, Brasil.1

\footnotetext{
* Email para correspondência: itsmatheusrodrigues@gmail.com
} 
líderes governamentais, chefes de estado, iniciativa privada, além de populares. Toda a sociedade estava atenta aos resultados discutidos na ECO-92 (Mesquita \& Medeiros, 2018).

Pode se destacar também a Conferência das Nações Unidas, Rio +20 , sobre o desenvolvimento sustentável, que ocorreu no período de 13 a 22 de junho de 2012, sediado na cidade do Rio de Janeiro. Nomeada em homenagem aos vinte anos da Rio-92. Teve o objetivo de renovar o compromisso político com o desenvolvimento sustentável. Os participantes avaliaram o progresso e as lacunas na adoção das decisões das principais cúpulas sobre o assunto e levantamento de novos temas. A Rio +20 abordou dois temas principais, a economia verde no contexto do desenvolvimento sustentável e da erradicação da pobreza; a estrutura institucional para o desenvolvimento sustentável (Comitê Nacional de Organização Rio+20, 2011).

Vale lembrar também a Agenda 21, que é um dos principais resultados da conferência Rio +20 e Eco92 (Francisco, 2019). Segundo o Ministério do Meio Ambiente, a Agenda 21 é definida como um instrumento de planejamento para a construção de sociedades sustentáveis, em diferentes bases geográficas, que tem como base os pilares da sustentabilidade: ambiental, social e economia (Ministério do Meio Ambiente, n.d.).

Segundo Nascimento, Leão e Rocha (2016), a construção civil ainda é o setor que mais consome os recursos naturais do planeta, podendo atingir um consumo de até $70 \%$. Diante de tais dados é necessário estudos acerca de novas formas de produzir,atendendo a demanda do consumo atual sem comprometer o meio ambiente que deixaremos para as próximas gerações.

A construção civil no Brasil é o setor que mais cresce anualmente, e com isso os impactos ambientais causados por essa indústria crescem juntos. Porém o Brasil se destaca cada vez mais quando se trata de construções sustentáveis. O país conta com sete organizações sustentáveis para construções e reformas que visam o desenvolvimento pró-ecológico. O mais utilizado é o LEED, criado pela USGBG (Green Building Council) nos EUA e adotado no Brasil desde 2007, com reconhecimento mundial e grande aceitação em território nacional, as certificações $L E E D$ tem crescido gradualmente no Brasil. Até o ano de 2016 o Brasil se encontrava em quinto lugar no ranking mundial de países com edificações certificadas (Santos, 2019).

O Brasil é referência mundial por grandes obras sustentáveis, como por exemplo, o estádio do Mineirão localizado em Belo Horizonte, Minas Gerais. Reformado para a copa Mundial de futebol em 2014, o estádio vem se mostrando cada vez mais eficiente após a sua modernização sustentável (Oliveira\&Faria, 2019). Sendo estádio pioneiro, primeiro e único na América do Sul a conquistar o nível mais alto do selo ambiental, o
LEED Platinum, e segundo no planeta, atrás apenas dos Estados Unidos, país de origem do $L E E D$, que obteve o primeiro estádio do planeta a conseguir alcançar o nível máximo da certificação, o estádio Mercedes-Benz Stadium (Leardi, 2017).

\section{Materiais e Métodos}

Por meio de revisão bibliográfica, os dados foram agrupados, sendo utilizados no desenvolvimento desse trabalho cartilhas, sites na internet e trabalhos acadêmicos sobre Certificação $L E E D$, sustentabilidade e a reforma do estádio Governador Magalhães Pinto, conhecido como Mineirão, concluída em 2014. As principais informações sobre o LEED foram adquiridas através da plataforma do órgão responsável pela certificação no Brasil, o GBC Brasil. E para o levantamento de dados sobre a reforma do estádio do Mineirão, nos moldes do $L E E D$, foi usado como principal ferramenta de estudo o site oficial do CTE - Centro de Tecnologias de Edificações, empresa que participou massivamente da reforma desse estádio.

\section{Sustentabilidade na Construção Civil}

O setor da construção civil é o maior vilão do meio ambiente, pois utilizaos recursos naturais massivamente para sua execução(Federação Brasileira de Bancos [BNDES], n.d.).Podemos conferir dados em porcentagem de insumos consumidos pela construção civil até o ano de 2007 como mostra a tabela 1 .

As certificações de sustentabilidade visam reduzir esses impactos causados pelo setor civil. No Brasil, atualmente temos sete tipos de certificações atuantes no mercado: quatro internacionais e três nacionais (Redação SustentArqui, 2014). A mais utilizada é a $L E E D$, a qual foi escolhida para seguir o checklist sustentável e obter a certificação para o estádio do Mineirão em 2014.

\section{Certificações Ambientais}

$\mathrm{Na}$ tabela 2 a seguir estão as sete entidades certificadoras presentes no Brasil, com seu ano de criação e organização responsável.

\section{Certificação $L E E D$}

\section{Como Funciona a Certificação $L E E D$}

Para submeter um projeto no $L E E D$ é necessário antes identificar em qual sistema o projeto se encaixa, existem quatro sistemas diferentes de acordo com o site do órgão oficial pelo LEED no Brasil, o GBG Brasil, 
Tabela 1. Impacto causadodevido ao consumopelo setorde construção civil até 2007.

\begin{tabular}{|c|c|}
\hline & Consumo (\%) \\
\hline Uso da Água & 21 \\
\hline Emissões Gases Efeito Estufa & 25 \\
\hline Eletricidade & 42 \\
\hline Resíduos & 65 \\
\hline
\end{tabular}

Tabela 2. Entidades Certificadoras no Brasil.

\begin{tabular}{|c|c|c|c|}
\hline Certificação & $\begin{array}{l}\text { Organização } \\
\text { Desenvolvedora }\end{array}$ & Criação & Origem \\
\hline $\begin{array}{c}\text { AQUA - Alta Qualidade } \\
\text { Ambiental do Empreendimento }\end{array}$ & $\begin{array}{c}\text { Fundação Vanzolini e } \\
\text { desenvolvido pelos professores da } \\
\text { Escola Politécnica da USP. }\end{array}$ & 2007 & Brasil \\
\hline $\begin{array}{c}\text { BREEAM - BuildingResearch } \\
\text { Establishment Environmental } \\
\text { Assessment Method }\end{array}$ & BuildingResearch Establishment & 1990 & Reino Unido \\
\hline $\begin{array}{c}\text { DGNB - Deutsche } \\
\text { GesellschaftfürNachhaltigesBau } \\
\text { en }\end{array}$ & $\begin{array}{c}\text { GermanSustainableBuilding } \\
\text { System }\end{array}$ & 2007 & Alemanha \\
\hline $\begin{array}{l}L E E D \text { - Leadership in Energy } \\
\text { and Environmental Design }\end{array}$ & Green BuildingCouncil & 1993 & Estados Unidos \\
\hline Selo Casa Azul Caixa & Caixa Econômica Federal & 2008 & Brasil \\
\hline $\begin{array}{c}\text { Programa Nacional de Eficiência } \\
\text { Energética em Edificações } \\
\text { (Procel Edifica) }\end{array}$ & $\begin{array}{l}\text { Ministério de Minas e Energia e } \\
\text { das Cidades e de Universidades e } \\
\text { Centros de Pesquisa }\end{array}$ & 2003 & Brasil \\
\hline Qualiverde & $\begin{array}{l}\text { Prefeitura do Rio de Janeiro / } \\
\text { Conselho Municipal de Política } \\
\text { Urbana - COMPUR }\end{array}$ & 2012 & Brasil \\
\hline
\end{tabular}


são eles:

LEED BD+C (Building Design + Construction), para projetos de novas construções ou grandes reformas, como o caso do estádio do Mineirão, reinaugurado em 2014, Envoltória e Núcleo Central, Escolas, Lojas de Varejo, Data Centers, Galpões e Centros de Distribuição, Hospedagem e Unidades de Saúde.

LEED ID+C (Interior Design + Construction), para projetos de designer interno voltado para uma melhor qualidade de vida humana pensando no meio ambiente, usado para interiores comerciais, lojas de varejo e hospedagem.

LEED $O+M$ (Operation \& Maintenance), para operação e manutenção de edifícios existentes, como por exemplo, lojas de varejo, escolas, hospedagem, data centers, galpões e centros de distribuição.

LEED ND (Neighborhood), para desenvolvimento sustentável do bairro mais sustentáveis. Considera a comunidade como um todo, desde os edifícios de alto desempenho, parques, espaços verdes, tráfego de carros, bicicletas e pedestres de forma organizada e eficiente. Disponível para bairro que ainda está no projeto ou foi até 75\% construído.(Green Building Council Brasil [GBC Brasil], 2014).

Após escolhido o sistema ao qual o projeto se encaixa, irão ser avaliados critérios que geram pontuação, esses são divididos em oito categorias:Localização e Transporte; Espaço sustentável; Eficiência do uso da água; Energia e Atmosfera; Materiais e Recursos; Qualidade ambiental interna;Inovação e Processos; Créditos de Prioridade Regional.

Após enviar o projeto para análise, ele será classificado em uma categoria, cada categoria tem uma pontuação máxima que pode ser alcançada, o somatório de todas é 110 pontos. Após a revisão, o projeto será classificado de acordo com a pontuação atingida, demonstrado na tabela 3 (GBC Brasil, 2014).

\section{Benefícios da Certificação LEED}

Nascimento et al. (2016) avaliam as certificações ambientais como uma resposta que o setor civil tem em relação às exigências da sociedade, visto que o mundo passa por um momento de crise ecológica, em que se deve pensar nos avanços tecnológicos, melhorando o dia a dia da sociedade sem causar impactos ambientais maiores na realidade atual, otimizando os problemas acarretados pelo desenvolvimento desenfreado da construção civil.

O LEED, assim como outras ferramentas de certificação sustentável para construções verdes que atuam no Brasil, é uma ferramenta que auxilia desde o projeto até a após a entrega do produto, auxiliando também nas operações e manutenções das construções. O que acontece é que muita gente já tentava construir de forma sustentável, porém sem um "manual” específico para isso e um órgão certificador para fiscalizar e dar crédito corretamente. Muitas construções ganhavam o reconhecimento por construir sem causar grandes impactos ambientais sem o devido mérito. A sociedade atualmente se interessa por construções sustentáveis por que percebe que o ramo do setor civil consome mais recursos naturais do que o planeta tem a oferecer. $\mathrm{O}$ que grande parte desconhece é que uma edificação sustentável gera uma grande economia também em longo prazo (Canazaro, Moraes, \& Kern, 2017).Podemos ver essas economias de acordo com a tabela 4.

Como pode se ver na figura 4, uma construção verde pode reduzir por exemplo o consumo de água em até $40 \%$, como sistemas de captação da água da chuva para sanitários, etc., reutilização de "águas cinzas" para jardinagem após o devido tratamento. Redução de energia consumida em até 30\% com construções pensadas em aproveitamento da luz solar durante o dia, arquiteturas estratégicas pensando na temperatura interna do ambiente, e até mesmo a produção de energia na própria construção, como por exemplo os painéis solares. Redução da emissão de $\mathrm{CO}_{2}$ quando um bairro é projetado para se ter o menor tráfego de automóveis que utilizam como combustível energia vinda de recursos não renováveis, que automaticamente reduzem as ilhas de calor nas grandes cidades, combinando os grandes centros com ciclovias, áreas verdes, etc. Redução de resíduos gerados através de reuso de materiais e descarte correto de resíduos (GBC Brasil, 2014).

Uma construção sustentável precisa ser bem estudada antes de ser executada, deve se fazer sempre um estudo de viabilidade do negócio. De acordo com Fujihara (2012), uma construção sustentável baseia-se nos conceitos de sustentabilidade, ambiental, economia e o bem-estar de seus usuários. O estudo da viabilidade deve seguir as seguintes etapas:Localização; Estudo de Concepção; Projeto Executivo; Construção; Operação; Manutenção e Geração e Remoção de resíduos (Fujihara, 2007).

\section{Custo vs. Benefício}

FEBRABAN(n.d.), as dificuldades encontradas no Brasil para seguir a diante com construções sustentáveis são devido a falta de estímulo governamental. O mercado de recursos sustentáveis enfrenta grandes dificuldades para se desenvolver, devidos às altas tarifas cobradas por encargos fiscais. Dessa forma, não há concorrência no mercado, e o custo de materiais certificados continua sendo um padrão muito alto.

Nascimento et al. (2016) afirmam que cerca de $70 \%$ dos recursos naturais do planeta são consumidos pela construção civil, um dado preocupante visto que se não for reformulada as práticas construtivas os insumos para o setor civil ficarão escassos. Diante de tais dados a sociedade se viu obrigada a repensar 
Tabela 3. Categorias pela pontuação.

\begin{tabular}{|c|c|}
\hline Categoria & Pontuação \\
\hline Certified & $40-49$ \\
\hline Silver & $50-59$ \\
\hline Gold & $60-79$ \\
\hline Platinum & $80+$ \\
\hline
\end{tabular}

FONTE: GBC Brasil (2014) ADAPTADO

Tabela 4. Economias com a utilização do sistema LEED.

\begin{tabular}{|c|c|}
\hline & Média de reduções no Brasil (\%) \\
\hline Água & $40 \%$ \\
\hline Energia & $30 \%$ \\
\hline CO2 & $35 \%$ \\
\hline Resíduos & $65 \%$ \\
\hline
\end{tabular}

FONTE: GBC Brasil (2014)

nas formas de adquirir produto, e com isso a sustentabilidade ganha força no comércio mundial de empreendimentos. Um usuário consciente prefere adquirir um produto que foi pensado no futuro, sem comprometer os recursos do planeta, pensando nas gerações futuras.

Embora tenham muitas dificuldades para seguir com um empreendimento sustentável, as certificações vieram para dar a devida credibilidade das construções que realmente seguem padrões de empreendimentos pensados nos pilares da sustentabilidade. Construir de forma sustentável se tornou mais válido que construir pensando somente em evoluir (Oliveira \& Faria, 2019).

Embora as vantagens de um edifício verde sejam indiscutíveis, ainda não é tão comum a aquisição dessa forma de construir no país por fatores financeiros e culturais (Nascimento et al., 2016). O custo inicial para investimento é muito alto quando comparado com construções convencionais, os materiais de uso exigidos pelo sistema, criado originalmente para seu país de origem, EUA, devem ser de origem com selo certificado, o que no Brasil não é tão fácil de encontrar, visto que maior parte das madeiras utilizadas no país para construções não são sustentáveis e as empresas que trabalham com selos ambientais vendem seus produtos num valor mais alto, devido a falta de concorrência no mercado e aos impostos elevados para sua implementação.

$\mathrm{O}$ resultado esperado das certificações ambientais no país tende a crescer cada vez mais, sempre em prol de desenvolver e construir a favor do bem-estar social, econômico e ambiental. A tendência é que progressivamente mais profissionais se capacitem para desempenhar trabalhos e pesquisas e assim alcançar melhores resultados no quesito desenvolvimento/ sustentabilidade. É importante observar a real intenção dos investidores na aquisição de 
Tabela 5. Benefícios da certificação LEED.

\begin{tabular}{|c|c|c|}
\hline Econômicos & Sociais & Ambientais \\
\hline $\begin{array}{c}\text { Diminuição dos custos } \\
\text { operacionais }\end{array}$ & $\begin{array}{l}\text { Inclusão social e aumento do senso } \\
\text { de comunidade }\end{array}$ & $\begin{array}{l}\text { Uso racional e redução da } \\
\text { extração dos recursos naturais }\end{array}$ \\
\hline Diminuição dos riscos regulatórios & Capacitação profissional & $\begin{array}{c}\text { Redução do consumo de água } \\
\text { e energia }\end{array}$ \\
\hline $\begin{array}{l}\text { Valorização do imóvel para } \\
\text { revenda ou arrendamento }\end{array}$ & $\begin{array}{c}\text { Conscientização de trabalhadores e } \\
\text { usuários }\end{array}$ & $\begin{array}{c}\text { Implantação consciente e } \\
\text { ordenada }\end{array}$ \\
\hline $\begin{array}{l}\text { Aumento na velocidade de } \\
\text { ocupação }\end{array}$ & $\begin{array}{l}\text { Aumento da produtividade do } \\
\text { funcionário; melhora na } \\
\text { recuperação de pacientes (em } \\
\text { Hospitais); melhora no desempenho } \\
\text { de alunos (em Escolas); aumento } \\
\text { no ímpeto de compra de } \\
\text { consumidores (em Comércios). }\end{array}$ & $\begin{array}{l}\text { Mitigação dos efeitos das } \\
\text { mudanças climáticas }\end{array}$ \\
\hline Aumento da retenção & $\begin{array}{c}\text { Incentivo a formecedores com } \\
\text { maiores responsabilidades } \\
\text { socioambientais }\end{array}$ & $\begin{array}{c}\text { Uso de materiais e } \\
\text { tecnologias de baixo impacto } \\
\text { ambiental }\end{array}$ \\
\hline $\begin{array}{l}\text { Modemização e menor } \\
\text { obsolescência da edificação }\end{array}$ & $\begin{array}{l}\text { Aumento da satisfação e bem-estar } \\
\text { dos usuários }\end{array}$ & $\begin{array}{l}\text { Redução, tratamento e reuso } \\
\text { dos resíduos da construção e } \\
\text { operação }\end{array}$ \\
\hline
\end{tabular}

Fonte: GBC Brasil (2014) - ADAPTADO.

imóveis sustentáveis, já que nem sempre o foco principal é o cuidado com o meio ambiente, e sim os interesses financeiros graças a grande demanda social em busca de novos empreendimentos com selos ambientais. $\mathrm{O}$ que não se pode negar é que, intencionalmente ou não, os grupos investidores estão contribuindo imensamente para uma nova sociedade pensada em prol do meio ambiente (Nascimento et al., 2016).

\section{A implementação da Certificação $L E E D$ em edificações}

Para obter o certificado em sua edificação basta adequar seu projeto, que pode ser inicial ou de reforma, para os requisitos solicitados nesse tipo de certificação. Atualmente já existem empresas brasileiras que oferecem esse tipo de serviço, como o CTE - Centro de Tecnologias de Edificações, que proporciona consultoria e gerenciamento especializado nessa área, e exerce sua função em terras brasileiras desde 1990 (CTE, 2013). Essa empresa participou massivamente das obras de reforma do conhecido estádio do Mineirão, localizado em Belo Horizonte, MG.

\section{A Implementação da Certificação $L E E D$ no Estádio do Mineirão}

O projeto de reforma dessa edificação tem por finalidade adotar soluções e tecnologias sustentáveis buscando amenizar os impactos gerados no meio ambiente durante a vida útil do estádio, procurando sempre garantir uma gestão consistente do empreendimento, englobando todo um sistema integrado de limpeza, utilização da água, resíduos, serviços, manutenção de equipamentos, gestão de energia, entre outras, com o objetivo de elevar a eficiência operacional e reduzir os impactos ambientais. O Mineirão conta com cerca de $51.000 \mathrm{~m}^{2}$ de área, o CTE - Centro de 
limpeza e manutenção do estádio são capacitados para se conscientizarem a respeito do uso correto da água, sem desperdiçarem. O sistema de irrigação que atua em campo também é eficiente, gasta menos água em comparação aos sistemas tradicionais.

Tratamento de dejetos: Em relação ao despejo de esgoto nas redes públicas, o estádio também tem um diferencial. Foi construída uma rede de pré-tratamento em que a qualidade do esgoto é monitorada durante o seu processo de decantação, etc., garantindo assim que o esgoto que chega nas redes públicas siga o padrão préestabelecido em projeto.

Energética: Comparado com o modelo de referência a economia de energia anual é de 43,73\%. Com a instalação do modelo VRF com condensação de ar foi possível economizar energia com o ar condicionado, foi instalado na bilheteria, delegacia e posto médico. Centrais de água gelada de alta performance foram instaladas nas dependências restantes do estádio, museu e lojas. O sistema de iluminação reduz certa de $30 \%$ da energia com a iluminação.Pensando no meio ambiente, o estádio gera energia limpa e renovável. A estrutura da cobertura conta com 9.500 metros quadrados construídos com cerca de 6.000 células de células de silício cristalino. Essa usina solar fotovoltaica de 1,42 MWP foi construída em parceria com a Cemig. Outra vantagem é que esse sistema não demanda tanta manutenção e tem uma vida útil longa.

Materiais e recursos: Foi criado um Plano de Gestão e Recursos, além de locais estratégicos para a coleta e armazenamento de materiais para reciclagem. Há também a realização de estudos gravimétricos para analisar melhorias dos resíduos gerados nos eventos. Foi aproveitada grande parte da estrutura já existente no estádio possibilitando a redução de material descartado e a utilização de novos, elevando a vida útil da estrutura existente. Os materiais que foram retirados do estádio antes da demolição foram doados para serem reaproveitados em outrosedifícios públicos. O volume de resíduos que foram reaproveitados foi de 79,44\%, o que diminui a quantidade de material mandado para aterros. Massivamente, $12,6 \%$ dos recursos utilizados no estádio são provenientes de conteúdo reciclável em sua composição. $49 \%$ do custo foram com materiais fabricados e extraídos em um raio de $800 \mathrm{~km}$.

Qualidade do ambiente interno: É proibido fumar dentro e em até 8 metros dos acessos do estádio. As fontes de emissão de poluentes dentro do estádio são controladas, foi criado um plano de controle de qualidade do ar interno, a fim de promover a qualidade e conforto dos usuários do estádio, como as tintas, revestimentos, adesivos e selantes que foram utilizadas, todas obedecem ao limite de compostos orgânicos voláteis, assim como foi estabelecido pelo órgão certificador. Até atividade de limpeza foram criadas tecnologias para reduzir o material particulado nos ambientes do estádio.
Reaproveitamento de resíduos: Além dos itens exigidos pelo $L E E D$, o estádio também tomou atitudes ecológicas inspiradas na torcida da japonesa durante um jogo na copa do mundo em 2004, em que toda a torcida recolhia o próprio lixo das arquibancadas para fazer o descarte correto. Em parceria com a Asmare (Associação dos Catadores de Papel, Papelão e Materiais Reaproveitáveis de Belo Horizonte), todo lixo recolhido pelos torcedores por incentivo do estádio é feito através de sacolas distribuídas pelos catadores da Asmare, que leva os resíduos recicláveis. Os não recicláveis são encaminhados para o aterro sanitário de macaúbas, que é licenciado. São encaminhados para compostagem os resíduos de poda do gramado (CTE, 2014; Estádio Mineirão, 2018).

\section{Resultados e discussão}

Os edifícios sustentáveis tem alto desempenho energético, ou seja, são capazes de produzir energia, tem sistemas de reaproveitamento de águas, dentre vários outros benefícios de maior independência, temos também o principal fator que agrega valor imobiliário ao mercado, a economia em longo prazo e a vida útil do produto já que são construções inteligentes, com maior autonomia, fatores esses que muitas vezes faz com que as empresas que buscam pelos certificados ambientais visam mais o lucro e credibilidade do que o comprometimento com o meio ambiente em si (Nascimento et al., 2016).

No caso do Mineirão, o projeto de reforma com compromisso sustentável foi um requisito exigido pelo BNDES para financiamento da obra. O que não se esperava era tamanha conquista, alcançando o nível máximo do selo ambiental com mais credibilidade no mundo, além da satisfação dos usuários. O Mineirão atingiu com sucesso as três esferas da sustentabilidade, na economia a longo prazo se obteve uma redução hídrica satisfatória, reduzindo em até $70 \%$ o consumo de água graças a seus sistemas inteligentes de reaproveitamento de águas pluviais captadas. A eficiência energética, produzida no próprio estádio graças ao sistema instalado de painéis fotovoltaicos na cobertura do estádio. Segundo Oliveira e Faria (2019), a estimativa de redução anual graças a eficiência energética chega atingir em média $\mathrm{R} \$ 1.987 .834,06$.

Nos impactos ambientais, além dos benefícios de reuso de águas pluviais e aproveitamento da luz solar convertida em energia, durante o processo de construção o volume de resíduos reaproveitados foi de quase $80 \%$.

No quesito social, tanto o espaço interno quanto externo foram pensados para melhor comodidade dos usuários. Com espaço melhor pensado para atender os usuários, o Mineirão conta com uma política de qualidade de ar interno, sendo proibido fumar dentro do estádio e nas proximidades das bilheterias. $\mathrm{O}$ entorno do 
Tecnologia de Edificações atuou diretamente no projeto sustentável do estádio, participando de todas as fases de operação da reforma, com a consultoria Green Building. Com o contrato de parceria publico privada (PPP) com o Governo do Estado de Minas Gerais, a Minas Arena, constituída pelas construtoras Construção, Egesa e HAP Engenharia foi contratada para a execução da reforma e modernização do Mineirão, sendo beneficiada podendo explorar a comercialização do estádio por um período de 25 anos (Centro de Tecnologia de Edificações [CTE], 2014).

Financiado pelo BNDES, o estádio Governador Magalhães Pinto, popularmente chamado de Mineirão, foi reformado para receber os jogos da copa de 2014, algumas das exigências para o financiamento era um padrão sustentável para o novo estádio, que também atendesse aos padrões FIFA. Para isso, foi escolhido o modelo de checklist LEED. O BNDES liberou uma verba de 400 milhões para a reforma, o recurso foi destinado à Minas Arena Gestão de Instalações Esportivas S.A. Além da reforma do estádio, foi objeto de licitação também o Complexo do Mineirão, que englobava além da arena o seu ambiente externo, a esplanada em seu entorno, estacionamento e a passarela de ligação ao Mineirinho (Banco Nacional de Desenvolvimento Econômico e Social, n.d).

O Mineirão é o segundo estádio do mundo a receber o selo LEED ${ }^{\circledR}$ (Leadership in Energy and Environmental Design). Se tornando o primeiro e único do Brasil a conquistar o nível máximo da certificação LEED for New Construction, concedida pela USBGC (UnitedStates Green BuildingCouncil), o

\section{LEED Platinum.}

O Mineirão então passa a ser reconhecido, após a certificação pelo seu alto desempenho ambiental projetado, como:redução de $43 \%$ do custo operacional com consumo de energia, diminuição de $76 \%$ no consumo de água potável com a demanda de bacias e mictórios sendo abastecida com água de reuso, e $100 \%$ de economia de água potável para irrigação nas áreas de paisagismo (CTE, 2014).

Como o estádio já era uma construção existente é possível determinar o que mudou no cenário da gestão de recursos dessa edificação, como afirmou Mariana Lympius, que é a consultora de projetos sustentáveis do CTE:

O fato de o projeto tratar de uma renovação massiva de um estádio já existente possibilita a comparação dos padrões de consumo de água e energia antes da reforma, por exemplo. Os resultados são muito visíveis e relevantes, mostra o quanto as estratégias escolhidas foram eficazes para minimizar o impacto sobre o meio ambiente e trazer conforto também aos usuários. Foi muito gratificante participar de um projeto que deixa um legado importante aos cidadãos brasileiros.(Lympius, 2014).
A certificação do estádio do Mineirão abre um importante precedente no Brasil, demonstrando que é possível realizar obras dessa magnitude, respeitando o meio ambiente e ao mesmo tempo maximizando a gestão eficiente dos recursos. Como relatou Fábio Pozzer, coordenador de obras sustentáveis do CTE:

A equipe dedicada à reforma do estádio Mineirão alcançou grandes feitos de projeto, engenharia e sustentabilidade, enfrentou com eficiência as dificuldades do curto prazo para entrega de uma obra associada ao grande volume de atividades, sempre planejando e executando os controles ambientais necessários. (Pozzer, 2014).

Os diferenciais sustentáveis e a economia no Mineirão são inúmeros, como os listados abaixo:

Terreno sustentável: Foram adotadas cercas filtrantes perimetrais e bacias de sedimentação, jatos de água contínuospara a redução da poeira nas vias de tráfego, prevenção e controle de erosão e sedimentação, controle de contaminação de solo e água. Foi posto cinco sistemas de lava rodas, para o reuso da água, redução do consumo de água e economia para a obra. No lugar da área de estacionamento foi construída a esplanada, que recebe visitantes mesmo em dias em que não ocorrem eventos.Vagas de estacionamento especiais para veículos de baixa emissão e baixo consumo visando incentivar e conscientizar a população para o uso desses veículos.Mais de $50 \%$ das vagas de estacionamento foram construídas nos subsolos. O sistema de captação de água de chuva retém um grande volume de água, o que ajuda a aliviar o sistema de drenagem público e possibilita um armazenamento grande de água para atividades no estádio. A membrana que cobre o Estádio foi feita com material de cor clara e alta reflexão solar, e a cobertura de concreto existente serve de base para a instalação dos painéis fotovoltaicos que geram energia.

Hídrica: Segundo dados divulgados no site oficial da GBC Brasil em setembro de 2014 a economia de água esperada para o estádio do Mineirão após a reforma sustentável seria de $76 \%$ no uso de dispositivos sanitários e $100 \%$ para irrigação de paisagismo. De acordo com dados publicados pelo site oficial do estádio em março de 2018 a economia geral de água utilizada para essas finalidades pode alcançar até $70 \%$. Toda essa economia acontece devido aos sistemas de reutilização de águas pluviais. O estádio conta com sistema de captação das águas das chuvas, seus reservatórios tem uma capacidade total de 5 milhões de litros, que abastece o estádio por um período de até 3 meses de estiagem. Além de economizar o recurso hídrico potável da rede pública, o sistema de reaproveitamento contribui para evitar enchentes, já que essa água coletada seria direcionada para rios. O estádio também utiliza de dispositivos hidráulicos inteligentes, que economizam o uso de água, como torneiras, válvulas de descarga e chuveiros. Os profissionais que atuam na 
estádio é de fácil acesso, e conta com uma área verde, cuja espécies cultivadas são nativas. Todo o complexo do Mineirão é interligado para facilitar o acesso, desde o ginásio Mineirinho até o Grandioso estádio do Mineirão, contando com um estacionamento especial para automóveis que emitem menos $\mathrm{CO}_{2}$ na atmosfera.

De acordo com os dados demonstrados, a conquista da certificação do Estádio do Mineirão e as suas reduções pode se afirmar que obras sustentáveis são de vital importância para a qualidade de vida futura e preservação do planeta. A conscientização ambiental atualmente se tornou uma nova "moda" entre a população e cada vez mais se percebe a sua importância no mundo do politicamente correto, o setor da construção civil esta aprendendo a se adequar e a se educar tornando possível o desenvolvimento sustentável.

\section{Conclusão}

Diante de tantas dificuldades encontradas para se construir de forma sustentável é possível observar na prática os benefícios que o selo verde traz para a sociedade e meio ambiente. Mesmo que as alterações no projeto do empreendimento gerem a necessidade de incluir no orçamento um investimento inicial mais elevado do que em construções convencionais, os benefícios que a construção sustentável proporciona em longo prazo e também nas etapas de construção da obra são muito satisfatórios financeiramente, ambientalmente e socialmente. Incentivos governamentais para empresas privadas e estatais ainda são poucos comparados a outros países mais desenvolvidos, no quesito sustentabilidade, entretanto o Brasil vem crescendo cada vez mais no setor da construção verde. As certificações ambientais são um grande passo rumo ao futuro, elas difundem o conceito de construções verdes para a indústria, estimulando a competição no mercado, o que torna seu alcance e produção muito maior, tornando os selos verdes também uma jogada de marketing no mercado imobiliário, uma vez que imóveis que possuem esse tipo de certificação se tornam mais valorizados devido à popularização da sustentabilidade e conscientização ambiental popular

\section{Bibliografia}

BNDES. (n.d). Banco Nacional de Desenvolvimento Econômico e Social. Recuperado em 16 Maio, 2019, de https://www.bndes.gov.br/wps/portal/ site/home/financiamento/navegador/finalidades/empreendimentos-reformae-ampliacao\#!/

Canazaro, C., Moraes, C. A., \& Kern, A. (2017). Avaliação do ciclo de vida e a certificação LEED. Fórum Internacional de Resíduos Sólidos, 7.

Comitê Nacional de Organização Rio+20. (2011). Rio+20. Recuperado em 3 Maio, 2019, de http://www.rio20.gov.br/sobre a rio mais 20.html

CTE. (2013). Centro de Tecnologia de Edificações. Recuperado em 12 abril, 2019, de http://www.cte.com.br/qualidade/
CTE. (7 de julho de 2014). Centro de Tecnologias de Edicações. Recuperado em 20 Abril, 2019, de http://www.cte.com.br/projetos/2014-07-07estadiomineirao-alcanca-nivel-maximo-da/

CTE. (2014). GBC Brasill. Recuperado em 10 maio, 2019, de http://www. gbcbrasil.org.br/sistema/case/portfolio certificados-MENOR set2014.63. pdf

Estádio Mineirão. (21 de Março de 2018). Mineirão. Recuperado em 10 Maio, 2019, de http://estadiomineirao.com.br/o-mineirao/imprensa/noticias/ mineirao-tem-politica-sustentavel-para-economia-de-recursos-hidricos/

Estádio Mineirão. (n.d.). Mineirão. Recuperado em 10 Maio, 2019, de http:// estadiomineirao.com.br/o-mineirao/imprensa/sustentabilidade/

FEBRABAN. (n.d.). Café com Sustentabilidade.Recuperado em 16 Abril, 2019, de https://cafecomsustentabilidade.febraban.org.br/pdfs/ cafecomsustentabilidade-0017.pdf

Francisco, W. (2019). Brasil Escola. Recuperado em 7 Maio, 2019, de https:// brasilescola.uol.com.br/geografia/eco-92.htm

Fujihara, M. C. (2007). IAB-SC.Recuperado em 2 Maio, 2019, de http://iabsc.org.br/concursofatmafapesc/wp-content/uploads/2012/08/16.00h-Maria Carolina Fujihara.pdf

GBC Brasil. (2014). Green Building Council Brasil. Recuperado em 20 Abril, 2019, de http://www.gbcbrasil.org.br/tipologia-leed.php

GBC Brasil. (2014). Green Building Council Brasil. Recuperado em 07 Abril, 2019, de http://www.gbcbrasil.org.br/sobre-certificado.php\#prettyPhoto

GBC Brasil. (2014). Green Building Council Brasil. Recuperdo em 4 Abril, 2019, de http://www.gbcbrasil.org.br/leed-BDC.php

GBC Brasil. (2014). Green Building Council Brasil. Recuperado em 4 Abril, 2019, de http://www.gbcbrasil.org.br/leed-IDC.php

GBC Brasil. (2014). Green Building Council Brasil. Recuperado em 4 Abril, 2019, de http://www.gbcbrasil.org.br/leed-OM.php

GBC Brasil. (2014). Green Building Council Brasil. Recuperado em 4 Abril, 2019, de http://www.gbcbrasil.org.br/leed-ND.php

GBC Brasil. (2014). Green Building Council Brasil. Recuperado em 10 Abril, 2019, de http://www.gbcbrasil.org.br/sobre-certificado. php\#prettyPhoto[iframe]/0/

Leardi, L. (21 de Novembro de 2017). Archdaily. Recuperado em 15 abril, 2019, de https://www.archdaily.com.br/br/883903/equipe-do-atlanta-falconstem-o-primeiro-estadio-dos-eua-a-receber-a-certificacao-leed-platinum

Mesquita, G., \& Medeiros, M. (2018). A certificação LEED como uma ferramenta norteadora da sustentabilidade na construção civil . Revista eletrônica de educação da Faculdade Araguaia, 97-106.

Ministério do Meio Ambiente. (n.d.). Ministério do Meio Ambiente. Recuperado em 3 Abril, 2019, de http://www.mma.gov.br/responsabilidadesocioambiental/agenda-21

Nascimento, T., Leão, D., \& Rocha, J. (2016). Certificação Ambiental na Construção Civil Brasileira. Revista Acadêmica Feol, 104

Oliveira, J. C., \& Faria, A. C. (2019). Impacto econômico da construção sustentável: a reforma do Estádio do Mineirão. urbe. Revista Brasileira de Gestão Urbana, 1-14

Redação SustentArqui. (20 de março de 2014). sustentarqui.com.br. Recuperado em 14 Maio, 2019, de https://sustentarqui.com.br/selos-paracontrucao-sustentavel/

Santos, A. (10 de Abril de 2019). Massa Cinzenta. Recuperado em 20 Maio, 2019, de https://www.cimentoitambe.com.br/brasil-segue-no-top-5-daconstrucao-sustentavel-mundial/

Senado Federal. (2012). Estocolmo marcou quebra de paradigma. Recuperado em 13 Abril, 2019, de http://www.senado.gov.br/noticias/Jornal/ emdiscussao/rio20/a-rio20/conferencia-das-nacoes-unidas-para-o-meioambiente-humano-estocolmo-rio-92-agenda-ambiental-paises-elaboracaodocumentos-comissao-mundial-sobre-meio-ambiente-e-desenvolvimento. aspx 